\title{
A INTERNACIONALIZAÇÃO DO DIREITO PENAL. UMA APROXIMAÇÃO TEÓRICA A PARTIR DO CRIME DE LAVAGEM DE CAPITAIS
}

\author{
Marcus Vinícius Xavier de Oliveira ${ }^{1}$
}

\section{Resumo}

Este artigo tem por objetivo discutir o fenômeno da internacionalização do Direito Penal, cujo caráter jurídico e político, de um lado, tem influenciado continuamente os direitos nacionais, e de outro lado, tem sido pouco debatido pela doutrina penal brasileira. Para tanto foi escolhido o crime de lavagem de dinheiro, espécie de crime internacional transnacional previsto nas principais Convenções Internacionais que tratam de crimes internacionais econômicos, como paradigma para se discutir e comprovar o problema proposto. Buscou-se, ao final, comprovar a necessidade da cooperação internacional em matéria penal como forma de se prevenir a ocorrência de fatos que, do ponto de vista da Sociedade Internacional contemporânea, atinge a interesses comuns de todos os Estados, em especial a partir dos regimes internacionais de lavagem de dinheiro, uma vez que, conforme demonstrado, não está sujeito à jurisdição de tribunais penais internacionais. A pesquisa circunscreveuse, portanto, ao procedimento de pesquisa bibliográfica, tendo-se adotado o método dedutivo.

Palavras-chave: Internacionalização do Direito Penal. Crimes Transnacionais. Lavagem de Dinheiro. Regimes Internacionais. Cooperação Penal Internacional.

\section{INTRODUÇÃO}

Uma das características mais destacadas do mundo contemporâneo é a difusão, por todo o mundo, de problemas que antes tocavam somente ao Estado. Temas como o meio ambiente, a economia, a cultura, a criminalidade, dentre outros, entendidos até certo momento como esferas exclusivas de decisão e de atuação do Estado, passaram a ocupar a agenda internacional envolvendo, numa tentativa de solução, decisões quer de caráter internacional - entre Estados -, quer transnacional - entre sociedades civis -, orientadas pelo princípio da cooperação internacional. Nesse sentido, afirma Markus Kotzur (Kotzur, 2012, p. 15):

Quanto mais intensivamente se ver o moderno Estado previdência na incapacidade de sozinho satisfazer as suas tarefas e quanto mais tiver de recorrer à cooperação com outros Estados, tanto mais precária se torna a brecha entre as obrigações comunitárias fáticas e a doutrina da autarquia soberana. O campo da economia oferece um exemplo disso. Dependente da cooperação, o Estado possui quando muito a "posição de contraforte de eficácia regional frente aos processos do tráfego global"; converte-se em "centro de condensação regional na estrutura das constelações de poder supraestatais”. Sua

\footnotetext{
${ }^{1}$ Professor Adjunto da Universidade Federal de Rondônia. Doutor em Direito Penal pela Universidade do Estado do Rio de Janeiro. Membro do Grupo de Pesquisa em Teoria Política Contemporânea. E-mail: marcusoliveira@unir.br
} 
singularidade, exclusividade e posição monopólica pertencem ao passado. Se a alternativa para o Estado nacional é, por exemplo, tomar medidas de política econômica ou de proteção ambiental somente mediante a cooperação entre Estados, ou não o puder fazê-lo em absoluto, então toda forma de associação nestas matérias é mais que um simples ato de garantia da soberania.

Em outras palavras, não é o Estado, mas os Estados, nem a sociedade nacional, mas a Sociedade Internacional, que podem, orientados pela ideia de cooperação internacional, fundada que está sobre o princípio da solidariedade, buscar soluções eficazes para problemas que tocam a todos os povos, entre os quais se encontra o gravíssimo problema da macrocriminalidade internacional. Com efeito, conforme Jésus-Maria Silva Sanchez, “[...] os fenômenos econômicos da globalização e da integração econômica dão lugar à conformação de modalidades novas de delitos clássicos, assim como à aparição de novas formas delitivas” (SILVA SANCHEZ, 2011, p. 103).

O presente trabalho se ocupará de dois aspectos inerentes a este aspecto da vida contemporânea. $\mathrm{O}$ primeiro pode ser concebido como um paradigma epistemológico, a internacionalização do Direito Penal, e o segundo como um seu tópico, o crime de lavagem de capitais.

Mas por que o crime de lavagem de capitais? Esta pergunta enfrenta duas respostas.

Primeiro, o crime de lavagem de capitais é um delito previsto nas principais Convenções Internacionais pactuadas no sistema das Nações Unidas (doravante ONU) em matéria de Direito Penal - Tráfico de Entorpecentes $^{2}$, Crime Organizado ${ }^{3}$, Contra a Corrupção ${ }^{4}$ e Contra o Financiamento do Terrorismo ${ }^{5}$, no que resta evidenciado o seu caráter transnacional, conforme, aliás, é reconhecido na Exposição de Motivos da Lei 9613/1998 (Lei de Lavagem de Capitais), que se reporta expressamente ao cumprimento das obrigações internacionais assumidas pelo Estado brasileiro quanto à persecução desse delito. ${ }^{6}$

Conforme João Carlos Castellar,

A legislação brasileira sobre lavagem se insere neste contexto, pois sua vinda a lume no nosso ordenamento jurídico é decorrência do Decreto no 154 , de 26/06/91, que ratificou a Convenção Contra o Tráfico Ilícito de Entorpecentes e Substâncias Psicotrópicas, a chamada Convenção de Viena, de 20/10/88 [..] Esta normativa internacional assinada pelo Brasil em 1988 e ratificada em 1991, assim como a aprovação em 1992, do Regulamento Modelo sobre Delitos de Lavagem Relacionados com o Tráfico Ilícito de Drogas e Delitos Conexos, além de outros compromissos no âmbito pan-americano, foram a fonte inspiradora da nossa legislação sobre o crime de lavagem de dinheiro (CASTELLAR, 2004,

\footnotetext{
${ }^{2}$ Convenção contra o Tráfico Ilícito de Entorpecentes e Substâncias Psicotrópicas, ratificada pelo Brasil através do Decreto Legislativo n. 162/1991.

${ }^{3}$ Convenção das Nações Unidas contra o Crime Organizado Transnacional, ratificada pelo Brasil através do Decreto Legislativo n. 231/2003.

${ }^{4}$ Convenção das Nações Unidas contra Corrupção, ratificada pelo Brasil através do Decreto Legislativo n. 348/2008.

${ }^{5}$ Convenção Internacional para a Supressão do Financiamento do Terrorismo, ratificada pelo Brasil através do Decreto Legislativo n. $769 / 2005$.

6 "8. Portanto, o presente projeto se constitui na execução nacional de compromissos internacionais assumidos pelo Brasil, a começar pela Convenção de Viena de 1988”. Disponível em www.coaf.fazenda.gov.br/downloads/Lei\%209613.pdf. Acessado em 20/04/2012, às 14:00:00.
} 
p.93).

Além disso, o crime de lavagem de capitais põe em relevo o liame cada vez mais estreito entre direito e economia no mundo globalizado, relação que pode ser interpretada a partir de dois paradigmas.

O primeiro é a teoria neoliberal, que em síntese, resgatando a ideia liberal de autorregulamentação da esfera econômica, defende, como consequência, a mínima (ou nenhuma) intervenção do Estado nesta esfera social. Esta mínima intervenção teria tanto o condão de afastar as regras gerais de regulamentação econômica no âmbito administrativo, remanescendo para o Estado o papel de mero fiscal em caso de abusos, mormente naquelas hipóteses que põem em risco as próprias regras do sistema capitalista (v.g., no âmbito da livre concorrência), como o de infirmar, absolutamente, a legitimidade da tutela penal no âmbito econômico. Para isto bastaria a sanção administrativa, e somente naquelas poucas hipóteses em que a intervenção fosse, juridicamente, legítima. Neste trabalho esta teoria é denominada non olet?

O segundo paradigma pode ser identificado com a teoria socialdemocrata, segundo a qual, mais uma vez em ligeira síntese, é necessário que o Estado intervenha no domínio econômico - quer por intermédio da regulamentação econômica, quer mediante o exercício de atividade econômica em concorrência com a iniciativa privada, seja ainda mediante o monopólio estatal de determinadas atividades econômicas essenciais à soberania nacional - com a finalidade de harmonizar, conforme prescrito na Constituição da República de 1988 (doravante CRFB/88), "[...] os valores sociais do trabalho e da livre iniciativa” (artigo 1º, inciso IV). O grau de intervenção estatal, inclusive no âmbito do Direito Penal econômico, que se desenvolverá a partir dessa teoria é, por assim dizer, cambiante.

Para Ricardo Corrêa Coelho esta contínua mudança pode ser identificada pela imagem de um pêndulo que oscila entre dois polos: à esquerda (onde mais?), se encontra o estado interventor, à direita, o mercado. Em determinados períodos históricos, ocorrerá, por motivos vários, a oscilação para a esquerda, na qual se opera uma maior intervenção do estado na esfera econômica (inclusive com a possibilidade de eliminação do próprio mercado, como o demonstra o sistema socialista de produção, e com um aumento significativo das normas penais), em outros períodos históricos prevalecerá uma intervenção mitigada do estado, com amplo grau de autonomia autorregulatória do próprio mercado. O ideal seria, pois, aquela posição intermediária de harmonia entre livre concorrência e intervenção estatal, benfazeja tanto para a autonomia privada como para o bem-estar

\footnotetext{
${ }^{7}$ Non olet ou pecunia non olet é um conceito jurídico e histórico. Juridicamente, na esfera do direito tributário, o brocardo irá indicar a capacidade tributária do Estado para tributar qualquer atividade econômica, independentemente de sua origem, lícita ou ilícita, bastando, portanto, a realização da hipótese de incidência tributária para que o fisco exija a exação do tributo. Nesse sentido, decidiu reiteradamente o Supremo Tribunal Federal (dovarante STF), nos HC 77530/RS, DJU de 18.9.98 e HC 94240/SP, DJU de 23.8.2011. Historicamente, non olet indica o diálogo entre Vespasiano, Imperador romano entre os anos 69 e 79 D.c., e seu filho Tito. Tendo aquele reinstituído a taxação pela utilização dos banheiros públicos em Roma, conforme já o fizera, v.g., Nero, seu filho Tito foi reclamar-lhe da origem (insalubre?) do dinheiro, no que Vespasiano, tendo pegado moedas provenientes da taxação, cheirou-as e logo após afirmou: "Non olet" (não tem cheiro).
} 
social (COELHO, 2008, pp. 24-29). Aqui esta teoria será denominada de pendular.

Pois bem, contemporaneamente, decisões acerca da intervenção do Estado nos mais diversos campos, inclusive através do Direito Penal econômico, não é uma decisão que caiba ao Estado Nacional em sua singularidade, mormente naquelas hipóteses em que estejam envolvidas a macrocriminalidade econômica, na qual o crime de lavagem de capitais desempenha um papel relevantíssimo, quer como meio pelo qual os grupos criminais logram obter a circulação do dinheiro obtido mediante atos ilícitos, quer no atinente à repressão de um e de outro, mas a uma decisão política conjunta de todos os Estados, como o demonstra, de forma emblemática, o surgimento daquilo que Isidoro Blanco Cordero denomina de regimes internacionais de prevenção e persecução do crime de lavagem capitais (BLANCO CORDERO, 2002, pp. 96-96).

Com isso não se quer, em absoluto, negar o princípio da soberania ${ }^{8}$, mas sim pôr em evidência a transformação pela qual têm passado (e sempre passaram) todos os institutos jurídicos, demandando da ciência jurídica aquela postura que Norberto Bobbio ${ }^{9}$ atribuía à doutrina do Direito Internacional, a saber, a contínua capacidade de se adaptar a realidade cambiante, sem, contudo, abandonar seus institutos e princípios essenciais.

Portanto, neste trabalho ecoa as teses de Peter Häberle (HÄBERLE, 2003; HÄBERLE, 2007) e Markus Kotzur (HÄBERLE, KOTZUR, 2003) que vêm, no âmbito do direito público, não a superação da soberania, mas a sua transformação no tipo Estado Constitucional Cooperativo, mormente na complexa tarefa de proteção aos direitos humanos, que, como se verá, não contrapõe-se em essência com a necessidade de persecução criminal.

\section{O PARADIGMA DA INTERNACIONALIZAÇÃO DO DIREITO PENAL}

A internacionalização do Direito Penal, enquanto paradigma epistemológico, é passível de ser caracterizado da seguinte forma: tanto a competência legislativa do Estado, como o exercício de seu poder persecutório em relação ao fenômeno criminal está, em graus bastante variados, vinculado ${ }^{10}$ ao sistema

\footnotetext{
${ }^{8}$ Conforme Markus Kotzur, "Quem abandona a soberania, desconhece não somente a realidade social, como também o conteúdo jurídico do conceito, assim como a simples necessidade que as comunidades políticas têm de contar com uma capacidade, competencialmente garantida, de atuação e configuração. Quem, por outro lado, continua sustentando a habitual, mas questionável equação entre povo, Estado e nação, não é menos cego ante a realidade e perante a necessidade de contar com uma noção de soberania que esteja em correspondência com ela". KOTZUR. A Soberania Hoje..., p. 2.

9 "Norberto Bobbio, ao resenhar o livro de Roberto Ago, Scienza giuridica e diritto Internazionale, aponta que é muito significativa a contribuição que dão os internacionalistas à Teoria Geral do Direito. Registra que, ao refletirem sobre um fenômeno jurídico em movimento, como é o caso do direito internacional, estão em melhores condições de liberar a Teoria Geral do Direito dos hábitos mentais e dos dogmas que derivam de consideraçōes baseadas exclusivamente no direito estatal". LAFER, Celso. Prefácio, in PERRONE-MOISÉS, Cláudia. Direito penal internacional: imunidades e anistias, São Paulo: Manole, 2012, p. xi.

${ }^{10}$ Por vinculação se há de compreender que os Estados, ao ratificarem um Tratado Internacional, estão obrigados a the darem cumprimento em atenção aos princípios pacta sunt servada e bona fide (artigo 26 c/c artigo 29 da Convenção de Viena sobre Direito dos Tratados entre Estados de 1969 (doravante CVDTE/69)). Isto implica, em ligeira síntese, no dever jurídico de agir conforme o que foi pactuado no Tratado Internacional, devendo-se, por regra geral, adequar o seu ordenamento jurídico aos termos daquela obrigação, de acordo com os princípios gerais e cultura jurídica do Estado. Nenhuma regra de direito interno, seja qual for a sua posição na hierarquia das fontes (isto para os ordenamentos jurídicos dotados de, pelo menos, constituições rígidas)
} 
internacional de cooperação internacional em matéria penal, sejam eles de caráter universal, através das diversas Convenções Internacionais pactuadas na ONU, seja de caráter regional, no âmbito, e.g., da União Europeia e da Organização dos Estados Americanos ${ }^{11}$, dos quais derivam obrigações de natureza legislativa, administrativa e de persecução, como, v.g., o dever de tipificação de comportamentos, a cooperação judiciária e policial entre Estados, a persecução penal etc. Referida internacionalização é consequência da reiteração de obrigações internacionais ratificadas pelos Estados em matéria penal, na qual prepondera o liame cada vez mais forte entre jurisdições nacionais e internacionais.

Por esse motivo, seguindo as lições de M. Cherif Bassiouni (BASSIOUNI, 2013, passim) e Carlos E. A. Japiassú (JAPIASSÚ, 2005, pp. 14-25), é que se pode conceituar a este ramo de Direito Penal Internacional, conceito que logra afastar à ainda persistente divisão Direito Penal Internacional e Direito Internacional Penal ${ }^{12}$. Segundo essa concepção tradicional, aquele se referiria às regras de conexão internas tendentes à solução de conflito interespacial de normas penais, bem como às regras também internas de cooperação judiciária, como, v.g., a extradição e a homologação de sentenças penais estrangeiras. Já este ao regime internacional de persecução dos crimes internacionais, cuja origem se encontra não em Nuremberg, mas no crime de pirataria, e hoje, no que diz respeita aos core crimes, no Estatuto de Roma do Tribunal Penal Internacional ${ }^{13}$. Como já afirmado supra, ambos são, no presente tempo, fixados por intermédio de diversos Tratados Internacionais gerais ou particulares, não tendo nenhum sentido a manutenção da dicotomia reportada, já que levaria a uma desnecessária compartimentação do estudo de um fenômeno - a internacionalização do Direito Penal - com perdas significativas no que concerne à sistematização.

A lógica que orienta o paradigma acima mencionado tem por infraestrutura aquilo que se tem denominado de globalização, duplamente caracterizada pelos conceitos de desterritorialização e reterritorilização. Sua fenomenologia decorre da emergência de relações sociais transnacionais cada vez mais amplas e dispersas, inclusive de caráter macrocriminal, na qual a competência do Estado para decidir acerca de suas políticas legislativas, econômicas, administrativas etc vem cedendo passo frente à Sociedade Internacional, que tem,

poderá servir de escusa para o inadimplemento da obrigação livremente assumida (artigo 27 da CVDTE/69; idem CVDTEOIS/86).

${ }^{11} \mathrm{Na}$ esfera da Organização dos Estados Americanos (doravante OEA), se destacam, para o tema do presente trabalho, a Convenção Interamericana contra o Terrorismo, que em seu artigo 4, estabelece um conjunto de ações necessárias para o enfrentamento do financiamento do terrorismo, em especial através da lavagem de capitais, bem como a Convenção Interamericana contra a Corrupção, que em seu artigo XV estabelece formas cooperativas entre os Estados da região para o enfrentamento da lavagem de capitais derivada de a corrupção.

${ }^{12}$ Nessa linha seguem PERRONE-MOISÉS, Direito penal internacional..., pp. 1-4; JANKOV, Fernanda F. F. Direito internacional penal: mecanismo de implementação do Tribunal Penal Internacional, São Paulo: Saraiva, 2009, pp. 1-8; DOTTI, René Ariel. Curso de direito penal: parte geral, Rio de Janeiro: Forense, 2004, p. 109.

${ }^{13}$ Sobre um panorama histórico sobre o desenvolvimento do direito penal internacional vide BASSIOUNI, M. Cherif. Universal jurisdiction for international crimes: historical perspectives and contemporary practice. Virginia Journal of International Law, n. 42, vol. 81,2001. 
reiteradamente, estabelecido parâmetros gerais de condução da governança nacional.

Dessa forma, desterritorialização e reterritorilização, no sentido que se emprega no presente trabalho, identificam o deslocamento dos centros de competência/decisão, vale dizer, do Estado para a Sociedade Internacional, na qual os Estados pactuam formas gerais para se enfrentar, em conjunto, determinados problemas internacionais que lhes são comuns.

Isto não quer significar, no entanto, atribuir ao Estado uma postura passiva, de mero receptor das regras externas. Quer significar, isto sim, uma transformação no processo de decisão política, na qual o Estado, inserido nos diversos fóruns internacionais sobre a determinação de uma possível política internacional, busca em relação aos demais negociadores internacionais (Estados, Organizações Internacionais, ONGs etc), estabelecer, dialogicamente, o conteúdo dessa política, de forma a tornar factível a compatibilização das normas internacionais com o seu ordenamento jurídico e as especificades de sua política interna acerca do fenômeno tratado. ${ }^{14}$

No que diz respeito ao Direito Penal, os Tratados Internacionais sobre essa temática estabelecem, em relação aos Estados signatários, obrigações de cooperação internacional tanto no que diz respeito à cooperação em sentido estrito (v.g.: a extradição, a cooperação policial e judiciária etc), quanto à tipificação de comportamentos e a persecução penal de delitos, quer tenham sido eles praticados no território do Estado ou no exterior.

Portanto, um conceito essencial para se compreender o tema é o de crime internacional, e que deve ser entendido como qualquer comportamento humano a que uma norma internacional, convencional ou consuetudinária $^{15}$, atribua, como uma consequência de sua realização, uma sanção penal, considerando-se, entretanto, que a persecução penal poderá ser exercida ou pelos próprios Estados, de conformidade com os seus ordenamentos jurídicos, ou por tribunais penais internacionais. Desse conceito surgem alguns problemas decorrentes da confluência entre Direito Penal e Direito Internacional.

A primeira alude não ao fato de que o Estado legisle sobre a matéria, mas que os Estados, no exercício de suas jurisdições internacionais, o façam. Nesse fato tem-se o pressuposto bastante evidente de que o comportamento humano de relevância jurídico-penal-internacional ofende, cumulativa ou alternativamente, ou a interesses comuns ou a interesses intrínsecos da Comunidade Internacional.

O segundo ponto problemático, especificamente grave para o Direito Penal de matriz liberal-garantista,

\footnotetext{
${ }^{14}$ Nesse sentido é que se deve compreender as cláusulas abertas contidas nos diversos tratados internacionais, em especial os que versam sobre direito penal, redigidas com as seguintes fórmulas: "em conformidade com sua legislação interna" (artigo 4, 1 da Convenção Internacional para a Supressão do Financiamento do Terrorismo); "de acordo com as disposições fundamentais de seus respectivos ordenamentos jurídicos internos” (artigo 2 da Convenção contra o Tráfico Ilícito de Entorpecentes e Substâncias Psicotrópicas) etc.

15 "Os aspectos penais do Direito Internacional derivam das "convenções", "costumes" e "princípios gerais do direito", todos os quais são uma das fontes dessa disciplina jurídica tal como enunciado no artigo 38 do Estatuto da Corte Internacional de Justiça”. BASSIOUNI, Introduction to international criminal law ..., 2013, p. 9 (livre tradução).
} 
decorre do fato de se considerar os costumes como fontes jurídicas de fatos impuníveis, na medida em que para este paradigma político-criminal, a única fonte legítima seria a lei formal ${ }^{16}$, e no Direito Internacional, os Tratados Internacionais.

Por fim, o terceiro foco de problemas respeita à circunstância de que a pessoa humana, e não o Estado seja sujeito passivo de uma sanção internacional, mais especificamente de caráter penal que, sem qualquer dúvida, é a forma mais grave de restrição à liberdade humana. Em outros termos, que o Direito Penal Internacional imponha uma sanção de caráter individual (à pessoa humana), e não coletiva (ao Estado) ${ }^{17}$.

Contudo, ao se analisar referidos problemas em seu devido contexto, verifica-se que:

1. A criação de normas jurídico-penais no âmbito da Sociedade Internacional não é nem fato novo nem extraordinário. Com efeito, o crime internacional par excellence ainda no âmbito do Direito Internacional westfaliano foi o de pirataria, podendo-se remontar a sua incriminação ao século XVI, tendo como fundamento doutrinário tanto a concepção ciceroniana de que o pirata se constituía em hostis humanis generis, como na doutrina de inúmeros internacionalistas da época (Alberico Gentili, Balthasar de Ayala e Hugo Grotius), para quem ela decorria de uma norma consuetudinária do Direito Internacional Geral, pela qual todo Estado detinha o poder-dever de persecução penal (BASSIOUNI, 2001, pp. 13-14) ${ }^{18}$.

2. No que toca, doutro giro, a se considerar o costume internacional como fonte legítima para a incriminação internacional não resta qualquer dúvida de que, à luz do paradigma liberal-garantista, ocorre, sim, violação ao postulado nullum crimen sine lege scripta. Contudo, nem a Sociedade Internacional é um super Estado, nem o princípio da rule of law aplica-se, integralmente, na conformação de seu ordenamento jurídico. Os costumes internacionais ainda são fontes por excelência do Direito Internacional ${ }^{19}$ - ao lado dos Tratados Internacionais -, sendo que, mormente no que toca aos crimes internacionais próprios, a acusação de violação ao postulado do princípio da legalidade em Direito Penal foi satisfatoriamente colmatado com a aprovação do ETPI e do seu Regulamento dos Elementos dos

\footnotetext{
${ }^{16}$ Para ficarmos em um de seus mais renomados teóricos "O primeiro destes elementos é o convencionalismo penal, tal como resulta do princípio da legalidade estrita, na determinação abstrata do que é punível. Este princípio exige duas condições: o caráter formal ou legal do critério de definição do desvio [...]. O desvio punível [...] É aquele formalmente indicado pela lei como pressuposto necessário para a aplicação de uma pena, segundo a clássica fórmula nullum poena et nullum criminen sine lege [...] A primeira condição equivale ao princípio da reserva legal em matéria penal e da consequente submissão do juiz à lei [...]. FERRAJOLI, Luigi. Direito e razão: teoria do garantismo penal, 2 ed., trd. Juarez Tavares et al., São Paulo: RT, 2006, pp. 38-39.

${ }^{17}$ KELSEN, Hans. Will the Judgment in the Nuremberg Trial Constitute a Precedent in International Law?, International Law Quaterly, v. 1, n. 2, summer 1947, pp. 15-171.

${ }^{18}$ BASSIOUNI, M. Cherif. Universal jurisdiction for international crimes: historical perspectives and contemporary practice, Virgínia Journal of International Law, n. 42, v. 81, fall 2001, pp. 13-14.

${ }^{19}$ GUGGENHEIM, Paul. Contribution a l'historie des sources du Droit des Gens, RCADI, vol. 94 (1958-II), p. 36 : « [...] la coutume, au point de vue de la doctrine, est la source originair et la plus importante. C'est d'elle que la seconde des sources, la convention tira sa validité $[. ..] \gg$
} 
Crimes (AMBOS, 2005, pp. 35-37).

3. Por fim, no que concerne ao princípio da responsabilidade direta do indivíduo perante o Direito Penal Internacional, uma clara dissonância em relação ao instituto da responsabilidade coletiva, é importante notar que ela se estabeleceu, com os Julgamentos de Nuremberg e Tóquio, como uma norma aceita pela Sociedade Internacional, mormente após a aprovação, pela AGONU, da Resolução sobre os Princípios do Direito Internacional Reconhecidos pela Carta do Tribunal de Nuremberg, de 1950, segundo o qual, em seu artigo $1^{\circ}$ "Qualquer pessoa que cometer um ato que constitua um crime sob o Direito Internacional é [por ele] responsável e passível de ser julgado" ${ }^{20}$, pelo que hoje não remanesce nenhuma dúvida quanto à sua legalidade e legitimidade (AMBOS, 2005, pp. 34-35).

Se, portanto, crime internacional é todo fato impunível criado pela ação coletiva dos Estados, remanesce o problema de se definir o como do exercício das jurisdições penais de persecução e adjudicação, vale dizer, o modo pelo qual os Estados e/ou os organismos internacionais exercem a persecução penal dos autores dos crimes internacionais. Para responder a este problema é preciso considerar que o exercício dessas competências leva em conta dois critérios distintos. A primeira diz respeito à dintingo entre crimes internacionais próprios e crimes internacionais impróprios, também denominados de crimes internacionais transnacionais. A segunda se reporta à conformação internacional entre a persecução penal de competência nacional, dita indirect enforcement, e a persecução penal de competência internacional, dita direct enforcement, sendo que a prática contemporânea do Direito Penal Internacional criou uma terceira variante, os tribunais internacionais mistos.

Com relação àquela primeira distinção, denominam-se crimes internacionais próprios, ou também core crimes, international crimes stricto sensu, crimes against international law, jus cogens international crimes, dentre outros (BASSIOUNI, 2013, p. 142), aos fatos impuníveis internacionais de maior gravidade no Direito Internacional, posto que ofendem os interesses, direitos e princípios fundamentais da Sociedade Internacional. Por isso são os crimes nucleares (core crimes) e, passados largos anos desde Nuremberg e Tóquio (os primeiros tribunais penais internacionais), foram definitivamente submetidos à jurisdição penal do TPI, muito embora vários desses crimes também sejam internacionalmente regulados por convenções internacionais específicas ${ }^{21}$. Assim, o crime de agressão, os crimes contra a humanidade, o genocídio e os crimes de guerra são fatos impuníveis internacionais porque, à luz da atual conformação da Sociedade Internacional, é inadmissível que os seus autores fiquem impunes, mormente porque esta impunidade é, por definição, fática, e não jurídica. Fática porque, nada

\footnotetext{
${ }^{20}$ ONU. "Principles of International Law Recognized in the Charter of the Nürnberg Tribunal and in the Judgement of the Tribunal”, Yearbook of the International Law Comission, 1950, vol. II, p. 97 (livre tradução).

${ }^{21}$ V.g. Convenção para a Prevenção e Repressão do Crime de Genocídio, a Convenção contra a Tortura e outros Tratamentos ou Penas Cruéis, Desumanos ou Degradantes e a Convenção Internacional para a Proteção de Todas as Pessoas Contra os Desaparecimentos Forçados, sendo que estes dois últimos crimes internacionais são também punidos na forma de crimes contra a humanidade, ex vido artigo $7^{\circ}$ do ETPI.
} 
obstante ser mais do que claro o rechaço político e jurídico de tais práticas, bem como a tipificação da maior parte destes crimes pelos próprios Estados e pelo Direito Internacional, a persecução penal em nível interno ainda se condiciona, em muitos casos, à ineficiência deliberada, querida e ilícita de quem esteja exercendo o poder, de fato ou de direito (AMBOS, KARAYAN, 1999, pp. 33-60) ${ }^{22}$. Nesse regime, o indivíduo será diretamente responsável perante a Sociedade Internacional.

Já os crimes internacionais impróprios, também denominados de international crimes largo sensu ${ }^{23}$ ou crimes transnacionais (BASSIOUNI, 2013, p. 142), são os fatos impuníveis internacionais que violam a determinados interesses da Comunidade Internacional, sejam eles pertinentes, vg., à prevenção de um determinado comportamento de caráter econômico (tráfico internacional de drogas, corrupção, criminalidade organizada etc) ou mesmo à violação de direitos humanos (tráfico internacional de pessoas, pornografia infantil etc) e que, por conveniência política, se ajustaram formas de prevenção geral e especial de dito comportamento mediante a cooperação penal internacional entre os Estados. São, sem qualquer sombra de dúvida, os mais numerosos, muitos deles de manifesta conotação econômica, pelo que também ocorreu a incriminação internacional da lavagem de capitais, forma de criminalidade financeira que atravessa, por assim dizer, todos os demais crimes transnacionais.

A distinção entre crimes internacionais próprios e impróprios é fundamental para a compreensão do como do exercício da jurisdição penal internacional na medida em que, sinteticamente, a prática de crimes internacionais próprios enseja a possibilidade de exercício de várias formas de jurisdição penal, seja pelos Estados - jurisdição penal concorrente entre competência territorial e jurisdição penal extraterritorial decorrente do princípio da justiça universal - e isso em razão da regra de conexão da incriminação internacional -, seja por Tribunais Penais Internacionais, em especial o TPI, que se orienta pelo princípio da complementariedade, nos termos dos artigos 1 e 17 do ETPI, isto é, quando os Estados-Membros do TPI não puderem ou não quiserem exercer a persecução penal. Complementariedade, nesse sentido, tem a mesma conotação de subsidiariedade. ${ }^{24}$

\footnotetext{
${ }^{22}$ Por todos, AMBOS, Kai, KARAYAN, Monica. Impunidad y derecho penal internacional, 2 ed., Buenos Aires: Ad Hoc, 1999, pp. 33-60.

${ }^{23}$ BASSIOUNI, Introduction to international criminal law..., p. 142.

${ }^{24}$ É importante frisar: o princípio da complementariedade se aplica ao TPI. Com relação ao Tribunal Penal Internacional para a ExIugoslávia (doravante ICTY) e ao Tribunal Penal Internacional de Ruanda (doravante ICTR), segundo William Schabas é regido pelo "[...] regime [...] conhecido por primazia, segundo o qual os tribunais ad hoc podem assumir a jurisdição de direito, sem a necessidade de demonstrar a falha ou insuficiências do sistema nacional [...]". SCHABAS, William A. An introduction to the International Criminal Court, 4 ed., Cambridge: Cambridge University Press, 2011, pp. 190-191. Com efeito, mencionados tribunais, em seus respectivos Estatutos, estabelecem o princípio da primazia de suas jurisdições sobre as jurisdições dos Estados nacionais, conforme, respectivamente, os artigos $1^{\circ} \mathrm{e}$ 9, 1 do EICTY, de 25 de maio de 1993 e os artigos $1^{\circ}$ e 8, 1 do ECTIR, de 08 de novembro de 1994. No mesmo sentido BAZELAIRE, Jean-Paul, CRETIN, Thierry. A justiça penal internacional: sua evolução, seu futuro de Nuremberg a Haia, trd. Luciana P. Venâncio, Bauru: Manole, 2004, pp. 95-97. Sobre os referidos Tribunais ad hoc consultar as excelentes monografias de HAGAN, John. Justice in the Balcans: prosecuting war crimes in the Hague Tribunal, Chicago: Chicago University Press, 2003 e CRUVELLIER, Thierrry. Court of remorse: inside the International Criminal Court for Rwanda, trd. Chari Voss, Madison: University of Wisconsin Press, 2006.
} 
Já os crimes internacionais impróprios ensejam somente a persecução penal de caráter nacional, territorial e/ou extraterritorial, inclusive na forma da jurisdição universal, em concorrência ou não entre o Estado territorialmente competente e outro que, segundo a sua legislação nacional, possa vir a exercer a persecução penal. Em outros termos, nenhum crime transnacional, como se dá nos casos já apontados de tráfico internacional de drogas, financiamento do terrorismo, corrupção e a lavagem de capitais a eles associados, está submetido à jurisdição de um Tribunal Penal Internacional. Nesse sentido, o indivíduo acusado da prática de um crime internacional impróprio somente será responsabilidade criminalmente se algum Estado, no exercício de sua jurisdição penal, exercer a persecução penal.

Aplica-se, como dito, aquilo que M. Cherif Bassiouni denomina de implementação indireta (indirect enforcement) dos crimes internacionais, já que, a rigor, todos os crimes previstos em Tratados Internacionais são, prima facie, internacionais. A implementação indireta é aquela estruturada sobre dois aspectos: a) incorporação nos ordenamentos nacionais dos crimes previstos em Tratados Internacionais (que Bassiouni denomina de "domestication of ICL"), e b) derivado da assunção dessas obrigações internacionais, os Estados assumirem a obrigação de cooperação internacional para a debelação do crime. É aquilo que Bassiouni denomina de "interstate cooperation in penal matters" (BASSIOUNI, 2013, p. 333).

A causa dessa internacionalização do Direito Penal se encontra naquilo que se pode identificar como macrocriminalidade transnacional, como o demonstram as hipóteses do tráfico internacional de entorpecentes, a criminalidade organizada transnacional, o terrorismo internacional e a lavagem de capitais decorrentes de tais fatos, e que em grande parte medida, desconsidera as limitações fronteiriças entre Estados, quando não a sua soberania territorial, como o demostra a situação sui generis de tomada de território no México e na Guatemala pelo grupo narcotraficante mexicano Los Zetas ${ }^{25}$.

Nisso, a internacionalização do Direito Penal se transforma em um instrumento da Sociedade Internacional para fazer frente aos problemas macrocriminais que não atingem ao Estado no singular, mas a própria Sociedade Internacional.

Para ilustrar esta necessidade de cooperação, é interessante ter em conta os valores obtidos pela macrocriminalidade internacional, conforme exposto no relatório do Escritório das Nações Unidas para Drogas e Crimes (doravante UNODC) - The globalization of crime: a transnacional organized crime threat assessment-, publicado em 2010 (UNODOC, 2010, pp. 16-17):

\footnotetext{
25 EL PAÍS. El cartel de la droga más sanguinario se adueña del norte de Guatemala. Disponível em http://elpais.com/diario/2011/05/19/internacional/1305756002_850215.html, acessado em 19/05/2011, às 19:30:00.
} 


\begin{tabular}{|l|c|}
\hline Atividade Ilícita & Valor Estimado - US\$ \\
\hline 1. Tráfico de pessoas para fins de exploração sexual. Destino: Europa & $3 \mathrm{bi}$ \\
\hline 2. Contrabando de imigrantes: & \\
\hline a) América Latina para EUA & $6,6 \mathrm{bi}$ \\
\hline b) África para Europa & $150 \mathrm{mi}$ \\
\hline 3. Tráfico de Cocaína: & $33 \mathrm{bi}$ \\
\hline a) Região Andina para EUA & $34 \mathrm{bi}$ \\
\hline b) Região Andina para Europa & \\
\hline 4. Tráfico de Heroína & $13 \mathrm{bi}$ \\
\hline a) Afeganistão para Federação Russa & $20 \mathrm{bi}$ \\
\hline b) Afeganistão para Europa (exceto Rússia) & \\
\hline 5. Tráfico de Armas & $20 \mathrm{mi}$ \\
\hline a) EUA para México & $33 \mathrm{mi}$ \\
\hline b) Leste-Europeu para Mundo & $8,2 \mathrm{bi}$ \\
\hline 6. Falsificação de Produtos - Ásia para Europa & $1,6 \mathrm{bi}$ \\
\hline 7. Falsificação de Remédios - Ásia para Sul e Leste Asiático e África & $100 \mathrm{mi}$ \\
\hline 8. Pirataria Marítima - Costa Somália & \\
\hline 9. Cybercrimes & $1 \mathrm{bi}$ \\
\hline a. Roubo de identificações/dados & $250 \mathrm{mi}$ \\
\hline b. Pornografia infantil & \\
\hline
\end{tabular}

Se a lavagem de capitais, como já afirmado, é um delito previsto nas principais convenções internacionais, universais e regionais, que versam sobre o problema, isto se deve ao fato dela ser um dos principais instrumentos utilizados pela criminalidade organizada para fazer circular, sem rastros de sua origem, a enorme soma de valores obtidos ilicitamente, e no caso do terrorismo internacional, obter o financiamento necessário para a manutenção dos grupos terroristas e/ou a execução dos atos de terrorismos que serão executados.

Esta característica do crime de lavagem de dinheiro, conforme se verá em tópico apropriado, influi concretamente na decisão internacional pela sua criminalização, tendo por fundamento considerações majoritariamente pragmáticos (BLANCO CORDERO, 2002, p. 95).

\section{A DÍADE PERSECUÇÃO-GARANTIA}

Um aspecto, entretanto, a que se tem dado pouca atenção no tema que se discute nesse artigo é a vinculação dos Estados aos regimes internacionais de proteção aos Direitos Humanos, nos quais se preveem garantias penais e processuais, sejam eles, mais uma vez, universais (Declaração Universal dos Direitos do Homem, os Pactos de 1969, Declaração de Direitos das Crianças etc), ou regionais (na União Europeia, a Convenção Europeia de Direitos do Homem e das Liberdades Fundamentais e os seus respectivos protocolos; no âmbito americano, o Pacto de San José da Costa Rica e os seus respectivos protocolos facultativos). 
Hans-Heinrich Jescheck, já no início da década de 1970, apontou esta intersecção entre Direito Penal e direitos humanos:

O movimento internacional para a "tutela dos direitos do homem" através do direito internacional, foi muito além do limite dos crimes contra a humanidade. Este desenvolvimento se completou em boa parte fora do direito penal, mas teve consequências notáveis também para o mesmo direito penal. Assim, já a declaração geral dos direitos do homem, feita pelas Nações Unidas no ano de 1948, contém uma série de princípios que servem para realizar o estado de direito especialmente no campo do direito penal e processual. A declaração da $\mathrm{ONU}$ tem, entretanto, apenas um peso moral e não é em si mesma uma norma jurídica vinculante. A International Covenant on Civil and Political Rights, de 19 de dezembro de 1966, ainda não está vigorando. Diferente é o caso da Convenção europeia para a tutela dos direitos do homem e das liberdades fundamentais, de 4 de novembro de 1950, que constitui matéria de direito internacional vinculante para os Estados, e que é considerada em certos países, entre os quais a República Federal alemã, como direito de aplicação imediata. $\mathrm{O}$ artigo $3 .^{\circ}$ desta Convenção veta penas ou tratamentos desumanos ou humilhantes, o que tem importância sobretudo para o desenvolvimento do regime penitenciário. $\mathrm{O}$ artigo $7 .^{\circ}$ fixa o princípio da legalidade para os crimes e para as penas. Ainda mais marcantes são as consequências da Convenção sobre direitos do homem no processo penal. Aqui encontramos, no art. $3^{\circ}$, a proibição da tortura, proibição que nos nossos tempos alcançou novamente uma triste atualidade. Tornaram-se normas de grande importância prática as do art. $5^{\circ}$ sobre a prisão preventiva, que levaram a uma vasta série de pronunciamentos por parte da Comissão europeia e da Corte europeia para direitos do homem. Deve ser lembrado, além disso, o importante artigo 6. da Convenção que fixa as condições mínimas de um "fair trial"europeu. (JESCHECK, 1972, p. 14)

Esta dupla vinculação, aqui identificada pela díade persecução-garantia, não está isenta de aporias conceituais nem de consequências práticas, conforme a ênfase recaia ora no aspecto repressivo ${ }^{26}$ ora no reforço das garantias, quando o correto seria, em nível ótimo, a harmonização entre as duas obrigações internacionais, vale dizer, compreender esta dualidade no raciocínio forjado por Carsten Stahn e Sven-R. Eiffler, ou seja, "o Direito Penal como braço estendido para a proteção geral dos direitos humanos" (AMBOS, 2008, p. 41).

Isto fica mais claro ao se aferir os diversos mandados constitucionais e em Tratados Internacionais de Direitos Humanos que determinam a criminalização de comportamentos como forma de se ensejar a máxime proteção de um direito humano fundamental. Nesse sentido, afirma Francesco C. Palazzo

[...] as vertentes orientadas no sentido da criminalização traduzem a expressão de uma visão
bem diversa do papel da Constituição no sistema penal; as obrigações de tutela penal no
confronto de determinados bens jurídicos, não infrequentemente característicos do novo
quadro de valores constitucionais e, seja como for, sempre de relevância constitucional,
constituem para oferecer a imagem de um Estado empenhado e ativo (inclusive
penalmente) na persecução de maior número de metas propiciadoras de transformação
social e da tutela de interesses de dimensões ultraindividual e coletivas, exaltando,
continuadamente, o papel instrumental do direito penal com respeito à política criminal,
ainda quando sob os auspícios - por assim dizer - da Constituição. As manifestações mais
unívocas no sentido da criminalização provêm das chamadas "cláusulas expressas de
penalização" (Verfassungstechtliche Pönalisierungsgebote) [...] (PALAZZO, 1989, p. 103).

\footnotetext{
${ }^{26}$ Basta lembrar as consequências deletérias que a war on drugs, financiada pelos EUA na Colômbia, e a war on terror no oriente médio, que nada propiciaram em termos de eficácia e de segurança.
} 
A nós nos parece evidente a inexistência de antinomia entre direitos humanos e Direito Penal ${ }^{27}$, devendo haver, conforme já dito, uma harmonização entre o dever de persecução e as garantias penal-processuais asseguradas constitucionalmente e pelo Direito Internacional da Pessoa Humana, o que se alcança, dentre outros institutos, por intermédio do princípio da proporcionalidade. Conforme observam Artur de B. G. Souza e Carlos E. A. Japiassú ao analisarem o papel que desempenha o princípio da proporcionalidade no Direito Penal, este princípio "[... objetiva, de imediato, uma justa correlação entre a gravidade do fato perpetrado pelo agente e a sanção penal correspondente [...] [que] deve ser obedecida tanto na elaboração, como na aplicação e na execução da lei penal" (SOUZA, JAPIASSÚ, 2012, p. 66).

Mas, conforme lembram os autores acima mencionados, o princípio da proporcionalidade se manifesta também na forma da proibição da insuficiência protetiva a um bem jurídico fundamental, como, v.g., se evidencia nas hipóteses de mandado constitucional (e no Direito Internacional da Pessoa Humana) de proteção a bens jurídicos por intermédio do Direito Penal, conforme, aliás, já decidiu o Supremo Tribunal Federal (doravante STF):

Controle e constitucionalidade das leis penais. Mandatos constitucionais de criminalização: A Constituição de 1988 contém um significativo elenco de normas que, em princípio, não outorgam direitos, mas que, antes, determinam a criminalização de condutas (CF, art. 5\%, XLI, XLII, XLIII, XLIV; art. 7º, X; art. 227, \$ 4º). Em todas essas normas é possível identificar um mandato de criminalização expresso, tendo em vista os bens e valores envolvidos. Os direitos fundamentais não podem ser considerados apenas como proibições de intervenção (Eingriffsverbote), expressando também um postulado de proteção (Schutzgebote). ${ }^{28}$

Em razão disso, é bastante óbvio que os objetivos que a Sociedade Internacional pretenda alcançar por intermédio do Direito Penal Internacional estarão duplamente limitados por dois princípios fundamentais: a) de um lado, a soberania estatal e a estrutura cultural de seu ordenamento jurídico. Nenhum Estado está, prima facie, obrigado a aderir a um determinado projeto internacional que não seja compatível com o seu poder de autodeterminação, nem sancionar um comportamento que seja incompatível com os princípios fundamentais de seu ordenamento jurídico, como, e.g., a criminalização de atos preparatórios no ordenamento jurídico brasileiro; b) de outro lado, pelas garantias penais e processuais presentes nas Constituições e nos Tratados Internacionais de Direitos Humanos, que são, ao mesmo tempo, fundamentos e limites para a legitimidade de qualquer projeto internacional, mormente nas hipóteses que envolvam a intervenção penal.

\section{A PREOCUPAÇÃO INTERNACIONAL EM TORNO A LAVAGEM DE CAPITAIS}

Os autores que tratam do tema ora em discussão são acordes em afirmar que a incriminação da lavagem

\footnotetext{
${ }^{27}$ Para uma excelente análise à luz das correntes liberal e analítica, NINO, Carlos Santiago. Ética e direitos humanos, trad. Nélio Schneider, São Leopoldo: Editora Unisinos, 2011, em especial o capítulo VIII - A justificação do governo: punição, pp. 329-381.
} 
de capitais decorreu, principalmente, por seu caráter transnacional (BLANCO CORDERO, 2002; BONFIM, BONFIM, 2005; MAIA, 2002), seja em razão da origem ilícita dos valores - tráfico internacional de entorpecentes, tráfico de pessoas, contrabando de armas, corrupção de caráter transnacional etc -, seja em razão do meio utilizado para se proceder a lavagem dos valores obtidos a partir de atos ilícitos, mormente a remessa de valores para paraísos fiscais mediante a utilização de empresas offshore, a aplicação nas bolsas de valores, no mercado imobiliário e em jogos e sorteios ${ }^{29}$. Conforme Deomar de Moraes, referindo-se à utilização dos paraísos fiscais e empresas offshore, afirma que:

[...] o que faz atraente um paraíso fiscal é o sigilo bancário impenetrável, a lavagem de dinheiro não ser considerada um crime, a capacidade reduzida de investigação e de coibição da prática de lavagem de dinheiro, a falta de identificação no fechamento de uma operação financeira, pouco controle de câmbio, uso de instrumentos monetários pagáveis ao portador [...].(MORAES, 2011, passim)

De acordo com a UNODC, o caráter transnacional da lavagem de dinheiro ganhou abrangência internacional de forma muito mais ampla em razão da globalização e do desenvolvimento da tecnologia de informação que se inicia a partir da década de 1970, o que possibilitou a mobilidade imediata de recursos no sistema financeiro internacional:

A Globalização gerou uma problemática para os bancos e instituições financeiras: com a digitalização da economia, reconhecer efetivamente seus clientes tornou-se um grande desafio. Isso porque agora, os bancos mantêm poucas relações físicas, face-a-face, com os titulares das contas. Assim, a vigilância, o controle e a fiscalização, que até então se utilizava dos registros e documentos financeiros, terão também que se digitalizar e incorporar novas tecnologias para combater os crimes financeiros de igual para igual. A lavagem de dinheiro tornou-se virtual. Isto é um fato. O novo mercado único, integrado e digitalizado, circula vultosos montantes de dinheiro em nanossegundos, e permite que o dinheiro viaje por diferentes jurisdições e fiscalizações domésticas, o que torna mais difícil ainda de se detectar a origem e a finalidade de cada transação. (UNODOC, 2012, s/ p.)

Entretanto, com isto não se quer negar, por obviedade, que a lavagem de dinheiro seja um crime de dimensão interna - valores adquiridos ilicitamente no país e nele reciclados -, mas a ênfase dos regimes internacionais é a de caráter transnacional, e que exercem uma forte influência na conformação legislativa e administrativa dos Estados no que toca à prevenção da lavagem de dinheiro.

Nesse sentido é interessante colher o exemplo da recente alteração por que passou a Lei n. 9613/1998 (Lei da Lavagem de Dinheiro) por meio da Lei n. 12.683/2012, em especial no que toca ao tema dos crimes antecedentes.

\footnotetext{
${ }^{28}$ SUPREMO TRIBUNAL FEDERAL. HC 104.410, Rel. Min. Gilmar Mendes, julgamento em 6-3-2012, 2a Turma, DJ de 27-32012.

${ }^{29}$ Para uma explanação mais pormenorizada, é interessante consultar a Cartilha: lavagem de dinheiro, um problema mundial, elaborada pelo Conselho de Controle de Atividades Financeiras - COAF, órgão brasileiro responsável pela fiscalização do sistema financeiro nacional no tema da lavagem de capitais, disponível em https://www.coaffazenda.gov.br/conteudo/publicacoes/cartilha-lavagem-de-dinheiro-um-problema-mundial/, acessado em 20/08/2012, às 22:00:00.
} 
Conforme Marcia M. M. Bonfim e Edilson M. Bonfim, o crime de lavagem de dinheiro consiste no "[...] processo composto por fases realizadas sucessivamente, que tem por finalidade introduzir na economia ou no sistema financeiro, bens, direitos ou valores procedentes de determinados crimes" (grifo nosso) (BONFIM, BONFIM, 2005, p. 15), ou segundo o conceito formulado pela Assembleia Geral da Organização Internacional de Polícia Criminal (doravante INTERPOL) "[...] qualquer ato ou tentativa tendente a ocultar ou encobrir a natureza dos ganhos ilegalmente obtidos de maneira que pareçam proceder de fontes lícitas" (BLANCO CORDERO, 2002, p. 169).

Se em ambos os conceitos figura como origem dos valores a fonte ilícita, isto se deve à razão de ser de referido crime, a saber, "Ocultar ou dissimular a natureza, origem, localização, disposição, movimentação ou propriedade de bens, direitos ou valores provenientes, direta ou indiretamente, de infração penal" (art. $1^{\circ}$ da Lei n. 9613/1998 com a redação dada pela Lei n. 12683/2012), isto é, ocultar ou dissimular são os verbos que descrevem os comportamentos delitivos caracterizadores do delito, por se tratar, conforme Carlos Rodolfo Tigre Maia, de típico crime parasitário, na medida em que está na dependência da ocorrência de um crime antecedente para que possa ser praticado (MAIA, 2007, p. 22).

O rol de crimes antecedentes - isto é, quais os delitos que, tendo sido praticados anteriormente à lavagem de dinheiro ensejariam a sua tipicidade - está compartimentado em quatro critérios distintos:

1. regime numerus clausus, segundo o qual somente ocorre lavagem de dinheiro tendo como crime antecedente um rol estrito de crimes;

2. o critério de classes: por esse sistema, a lavagem de dinheiro terá como crime antecedente uma classe de crimes previstas na legislação penal, tal como, v.g., estabelecido pela Convenção de Palermo em seu $\operatorname{artigo~} 2^{\circ} \mathrm{c} / \mathrm{c}$ artigo $6^{\circ}, 2$, b, isto é, um "[...] ato que constitua infração punível com uma pena de privação de liberdade, cujo máximo não seja inferior a quatro anos ou com pena superior;";

3. o critério abrangente de infração penal: por este critério, qualquer modalidade delituosa (sem distinção, v.g., entre crime e infração penal, crime de menor potencial ofensivo e crime grave (nos termos da Convenção de Palermo) etc) que tenha por consequência a geração de ativos de origem ilícita; e

4. o critério misto: neste, ocorre uma combinação daqueles crimes previstos em Convenções Internacionais, com outro critério, e.g., o de crime grave.

A Lei 9613/1998, antes da alteração legislativa feita pela Lei 12683/2012, conforme fica evidente na redação original de seu artigo $1^{\circ}$ (com a redação dada pela Lei n. 10701/2003, que alterara, dentre outros dispositivos, os incisos II e VIII), adotava o critério numerus clausus, a saber, somente seriam crimes antecedentes para fins de criminalização do crime de lavagem de dinheiro os: I - de tráfico ilícito de substâncias entorpecentes ou drogas afins; II - de terrorismo e seu financiamento; III - de contrabando ou tráfico de armas, munições ou 
material destinado à sua produção; IV - de extorsão mediante sequestro; V - contra a Administração Pública, inclusive a exigência, para si ou para outrem, direta ou indiretamente, de qualquer vantagem, como condição ou preço para a prática ou omissão de atos administrativos; VI - contra o sistema financeiro nacional; VII - praticado por organização criminosa; VIII - praticado por particular contra a administração pública estrangeira.

Com a nova redação dada pela Lei 12683/2012, o critério adotado foi o abrangente de infração penal, conforme se infere de sua redação: "Ocultar ou dissimular [...] provenientes, direta ou indiretamente, de infração penal" (grifo nosso), sem qualquer distinção, prima facie, entre crime e contravenção penal, crime de menor potencial ofensivo ou crime grave etc. Prima facie em razão da possibilidade de, no caso concreto, se discutir a tipicidade da lavagem em relação a um determinado crime ou contravenção penal, já que, ao menos abstratamente, nada ilide a que se conclua que qualquer ilícito penal do qual decorra lucro para o seu perpetrador seja considerado como antecedente para a ocorrência da lavagem de dinheiro.

Portanto, o critério adotado pelo legislador nacional na reforma da Lei de Lavagem de Dinheiro é condizente com o disposto no artigo 6 , 2, a da Convenção de Palermo ("Cada Estado Parte procurará aplicar o parágrafo 1 do presente Artigo à mais ampla gama possível de infrações principais") e o artigo 1º, e da Convenção Relativa ao Branqueamento, Detecção, Apreensão, e Perdas do Produto do Crime, dita de Estrasburgo de 1990 ("Infração principal” designa qualquer infração penal em consequência da qual são gerados produtos, os quais são suscetíveis de se tornarem objeto de uma infração nos termos do artigo $6^{\circ}$ da presente Convenção").

Interessante notar que o Brasil não é signatário da Convenção de Estrasburgo de 1990 - trata-se de Tratado Internacional pactuado no âmbito da União Europeia, mas que conseguiu atrair a adesão de Estados alheios ao regime comunitário, conforme projeto original da Comissão Europeia, como os Estados Unidos da América, Canadá e Austrália (BLANCO CORDERO, 2002, p. 109), como forma de congregar o maior número possível de Estados no projeto comunitário de combate à lavagem de dinheiro -, mas que nem por isso deixou de se influenciar por aquele regime internacional de combate à lavagem de capitais.

Conforme Isidoro Blanco Cordero, a preocupação da Sociedade Internacional com o problema da lavagem de dinheiro se deve, especialmente, a um critério pragmático no que toca ao enfrentamento da macrocriminalidade transnacional. A persecução penal seria claudicante caso se concentrasse somente nos crimes principais. Para que haja eficácia na prevenção, por exemplo, do tráfico internacional de entorpecentes, é necessário que os lucros dele provindo, e que, em sua maior parte, são lavados através do sistema financeiro internacional, sejam investigados e submetidos ao processo de bloqueio e apreensão como forma de, senão impedir, pelo menos tornar mais custosa, mais difícil essa atividade ilícita, além de subtrair do grupo criminoso a razão de sua atividade ilícita: o lucro. A prevenção, portanto, deve ser feita em duas frentes, de um lado na atividade principal, de outro, no resultado dessa atividade, e o resultado nunca será o tráfico per se, mas o lucro obtido com a 
atividade criminosa.

Entende o autor acima citado, que:

A estratégia internacional de luta contra a criminalidade que gera enormes lucros tem duas vertentes: a referente a apreensão e confisco dos bens, tendente a privar os delinquentes dos lucros obtidos de seus delitos, e a relativa aos esforços dirigidos a tipificar penalmente o branqueamento de capitais tanto no Direito Internacional como no Direito interno. Para por em funcionamento referida estratégia é preciso articular mecanismos de cooperação interestatal que garantam a aplicação do Direito Internacional de maneira eficaz e impeçam às organizações criminais subtrair-se ao mesmo. [...] na atualidade o problema da luta contra o branqueamento de capitais não se centra exclusivamente nos bens originados no tráfico de drogas, mas vai mais além e se refere a todas aquelas atividades criminais, fundamentalmente de caráter grave, que produzem ganhos substanciais. Isso se reflete também no âmbito dos instrumentos internacionais que, longe de limitar-se a regular o branqueamento de capitais procedente do tráfico de drogas, adotam um enfoque mais amplo e que se referem a bens procedentes de qualquer delito. (BLANCO CORDERO, 2002, p. 95)

É signo da preocupação internacional a proliferação dos regimes internacionais para regulamentação da lavagem de dinheiro. O que caracteriza um regime internacional como forma institucional diversa das organizações intergovernamentais é tanto a sua autonomia organizacional em relação a estas por conta da especificidade da matéria tratada (v.g., um regime internacional sobre lavagem de capitais não se preocupará com a criminalidade em geral, mas especificamente dessa temática, diversamente da INTERPOL), quanto a sua competência internacional para a formulação de procedimentos, atividades e normas sobre a questão. Contudo esta autonomia não pode ser compreendida como sinônimo de isolamento institucional. Muito pelo contrário. Se os regimes internacionais têm logrado estabelecer normas e procedimentos cooperativos para o combate à lavagem de dinheiro é em razão do apoio e adesão que os Estados, Organizações Internacionais e demais instituições internacionais aportam em favor dos mesmos.

Nesse ponto específico, a Convenção de Mérida (Convenção das Nações Unidas contra a Corrupção) oferece um motivo importante para fundamentar esse raciocínio, já que em seu artigo 14, 4 (este artigo trata especificamente do problema da lavagem de dinheiro provindos da corrupção) expressamente prescreve que "4. Ao estabelecer um regimento interno de regulamentação e supervisão de acordo com o presente Artigo, e sem prejuízo do disposto em qualquer outro Artigo da presente Convenção, recomenda-se aos Estados Partes que utilizem como guia as iniciativas pertinentes das organizações regionais, interregionais e multilaterais de luta contra a lavagem de dinheiro".

Em outros termos, o objetivo dos Estados não é a de, a cada novo acordo internacional, criar, ex nihilo, um novo procedimento de combate à lavagem de dinheiro, mas reforçar, permitir a cooperação, a eficácia, o aperfeiçoamento, dos regimes já existentes.

O exemplo mais interessante nesse sentido é o Grupo de Ação Financeira Internacional (doravante GAFI), instituído no ano de 1989 pelo então Grupo dos Sete Países mais Industrializados, hoje denominado de 
G8.

O GAFI foi instituído por ocasião da 15a Reunião Anual do G7 ocorrido na cidade de Paris, ocasião em que estes Estados se comprometeram a estabelecer a cooperação internacional em quatro temas principais: tráfico de entorpecentes, lavagem de capitais, terrorismo e meio ambiente. À época de sua criação o GAFI ganhou a adesão dos G7, tendo seu Tratado constitutivo sido aberto à ratificação de outros Estados, contando hoje com 36 Estados e 2 Organizações Regionais (Comissão Europeia e o Conselho de Cooperação do Golfo) na qualidade de membros e mais de 30 Organizações Internacionais, regionais e universais, na qualidade de observadores, que utilizam as Recomendações da GAFI para o enfrentamento da lavagem de dinheiro ${ }^{30}$.

Inicialmente o GAFI se preocupou em estabelecer formas de cooperação internacional para enfrentar o problema da lavagem de dinheiro provindo do tráfico de entorpecentes, estabelecendo, nesse sentido, um regime internacional com vistas à implementação da Convenção de Viena sobre Drogas de 1988, tendo instituído em abril de 1990 a Task Force Report 1, que estabeleceu, dentre outros critérios, o conceito de lavagem de dinheiro, de medidas provisórias e de confisco dos bens e valores, procedimentos de identificação de clientes e do dever de prestar informações às autoridades financeiras dos Estados partes etc. (BLANCO CORDERO, 2002, pp. 155160) Em razão disso, "[...] o GAFI se converteu no organismo internacional e de caráter intergovernamental mais importante do mundo na luta contra o branqueamento de capitais" (BLANCO CORDERO, 2002, pp. 158-159). Isso fica evidenciado no que toca ao problema das fases procedimentais que se utilizam para se proceder a lavagem de dinheiro.

Paolo Bernasconi falará de duas fases - lavagem e reciclagem - para identificar os procedimentos de ocultação da origem ilícita do dinheiro (através, e.g., da remessa de valores para paraísos fiscais ou aplicação no mercado imobiliário), fase identificada com a "lavagem", e os procedimentos adotados para a reinserção destes valores no sistema financeiro já "alvejados", identificado como "reciclagem", que no étimo, como se pode depreender, consiste em dar um novo ( $r e$ ) ciclo àquele dinheiro. Já Isidoro Blanco Cordero, reportando-se às lições de André Zünd, falará de dez fases, utilizando-se figurativamente do ciclo natural das águas para identificálas (precipitação, infiltração, corrente de águas subterrâneas, lagos subterrâneos, nova acumulação em lagos, estação de bombeamento, estação de depuração, aplicação ou aproveitamento, evaporação, nova precipitação).

Contudo, o critério mais difundido e utilizado é aquele adotado pelo GAFI, que identifica o procedimento em três fases distintas:

1. colocação: objetiva colocar os valores percebidos no sistema financeiro de forma a afastá-los de uma associação imediata com a sua origem ilícita;

\footnotetext{
${ }^{30}$ Informações colhidas no sítio da GAFI http://www.fatf-gafi.org/pages/aboutus/membersandobservers/\#d.en.3147, acessado em 20/08/2012, às 15:32:00.
} 
2. ocultação: objetiva, por intermédio de várias movimentações financeiras, encobrir os próprios recursos, de forma a se impedir o seu rastreamento pelas autoridades financeiras e de persecução penal; e

3. integração: objetiva reinserir os valores aferidos em favor dos beneficiários do processo de lavagem, de forma a permitir a sua utilização sem que remanesça qualquer traço de sua origem ilícita.

É importante notar, por fim, que o GAFI é somente um exemplo a ser colhido dentre tantos outros regimes internacionais de combate à lavagem de capitais, que ora adotam uma configuração regional - v.g., no âmbito da Organização dos Estados Americanos (doravante OEA), ora uma configuração mais abrangente, mas que se reportam a um conjunto de normas internacionais (as quatro Convenções da ONU já mencionadas), ou a outro regime internacional de lavagem de dinheiro (GAFI, Comitê de Basiléia sobre a Lavagem de Capitais etc), formando uma rede de cooperação e de troca de informações que se revestem de significativa importância para o enfrentamento da lavagem de dinheiro.

É obvio, portanto, não só o caráter transnacional do crime de lavagem de dinheiro, como também, e principalmente, o papel que desempenha a cooperação internacional no enfrentamento do problema.

\section{CONCLUSÃO}

A título de conclusão, retomemos àquelas duas teorias que orientam a relação entre direito e economia, e que acima foram identificadas pelas rubricas non olete pendular.

Parece ser uma característica da ciência moderna a operatividade de um raciocínio outou (natureza ou cultura; direito ou moral; liberdade ou autoridade; mercado ou Estado etc), quando a realidade da vida em sociedade é muito mais complexa e ambígua do que isso. Provavelmente isto se deve, dentre outras coisas, pela compartimentação das áreas do pensar em estâncias isoladas, sem que se busque o necessário liame entre as diversas disciplinas, de forma a se permitir uma compreensão mais ampla e pertinente da realidade.

De fato, pecunia non olet, mesmo porque, no atual estágio da sociedade da informação e do conhecimento, não se fala mais na circulação do dinheiro em espécie, mas de informações contábeis digitais na cifra de bilhões de algumas poucas moedas que são movimentadas interbancariamente de um polo a outro do globo terrestre em questões de segundos. Não só do Chuí ao Caburaí no Brasil, mas de Nova Iorque para Pequim, de Londres para Pequim, sem que os Estados logrem, sozinhos, controlar o seu fluxo.

Se o fluxo global de capitais permite os investimentos internacionais legítimos, permite também o encobrimento de enormes cifras oriundas da prática de ilícitos que, de acordo com a consciência mundial de nosso tempo, devem ser enfrentados, dado o enorme dano que causam às sociedades em geral, mas principalmente a pessoas concretas no particular. Uma ciência social que não busca aferir a própria realidade é uma ciência pejada por uma cegueira intencional, e que se apega mais a princípios abstratos do que à sua razão de 
ser: estabelecer parâmetros práticos para a solução de problemas concretos da vida. Negar a validade eo ipso da intervenção estatal na economia em geral, e do Direito Penal em particular por uma abstrata consideração acerca do conceito de ultima ratio não parece ser o raciocínio mais condizente com o momento em que o mundo se encontra.

Contudo, esse argumento não pode levar àquela polaridade pendular na qual o Estado passa a ser o único agente econômico, anulando qualquer possibilidade de ação econômica particular, ou que tenha no Direito Penal o principal instrumento de controle sobre a atividade econômica. "Nem tanto ao mar nem tanto à terra": contra a lógica do ou-ou a lógica da complementariedade e da harmonização.

O programa internacional de combate à lavagem de dinheiro parece indicar um caminho importante para o enfretamento da macrocriminalidade transnacional, já que objetiva atingir aos grupos criminosos no motivo pelo qual praticam os ilícitos: a obtenção de um lucro desmedido, pondo em risco de corrosão não só a autoridade dos Estados como a coesão social. Não nos parece desmedido nem ofensivo ao princípio da subsidiariedade a persecução penal orientada por essa finalidade, mesmo porque, a própria CRFB/88 legitima a intervenção penal na esfera do direito econômico (artigo $173, \mathbb{} 5^{\circ}$ ), sem que com isso se possa infirmar a ilegitimidade do próprio mandado constitucional.

A internacionalização do Direito Penal, nesse sentido, se constitui em um conjunto de instrumentos perfeitamente legítimos para o enfrentamento do problema dos crimes internacionais, posto que fixa, mediante a atuação conjunta do Estados, parâmetros comuns e institucionais para a atuação cooperativa. Conforme Celso de Mello: "A luta contra o crime somente será eficaz com a cooperação internacional". (MELLO, 2002, p.976)

\title{
THE INTERNATIONALIZATION OF CRIMINAL LAW. A THEORETICAL APPROACH FROM THE MONEY LAUNDRY
}

\begin{abstract}
This article aims to discuss the phenomenon of internationalization of criminal law, which have a legal and political character, and which, on the one hand, has continuously influenced national laws, and on the other hand, has been little debated by Brazilian criminal doctrine. In order to do so, the crime of money laundry, a kind of international transnational crime foreseen in the main International Conventions of transnational crimes was chosen as the paradigm to discuss and prove the problem proposed. In the end, it was tried to prove a need for international cooperation in criminal matters as a way to effectiveness the prevention by the implementation the international money laundering regimes, since, as shown, money laundering not subject to the jurisdiction of international criminal tribunals and depend of the indirect enforcement. The procedure of research adopted was the bibliographic research, and the method, deductive.
\end{abstract}

Keywords: Internationalization of Criminal Law. Money laundry. Transnational Crimes. International Regimes. International Criminal Cooperation. 


\section{REFERENCIAS}

AMBOS, Kai, KARAYAN, Monica. Impunidad y derecho penal internacional, 2 ed., Buenos Aires: Ad Hoc, 1999. La parte general del derecho penal internacional: bases para una elaboración dogmática, trd. Ezequiel Malarino, Berlin/Montvideo: Konrad-Adenauer Stiftung, 2005.

BASSIOUNI, M. Cherif. Universal jurisdiction for international crimes: historical perspectives and contemporary practice. Virginia Journal of International Law, n. 42, vol. 81, 2001.

Introduction to international criminal law, 2th edition, Leiden: Martinus Nijhoff Publishers, 2013.

BAZELAIRE, Jean-Paul, CRETIN, Thierry. A justiça penal internacional: sua evolução, seu futuro de Nuremberg a Haia, trd. Luciana P. Venâncio, Bauru: Manole, 2004

BLANCO CORDERO, Isidoro. El delito de blanqueo de capitales, 2 ed., Navarra: Aranzadi, 2002.

BONFIM, Maria M. M., BONFIM, Edilson M. Lavagem de dinheiro, Malheiros, 2005.

CASTELLAR, João Carlos. Lavagem de dinheiro: a questão do bem jurídico, Rio de Janeiro: REVAN, 2004.

COAF. Cartilha: lavagem de dinheiro, um problema mundial, disponível em https://www.coaffazenda.gov.br/conteudo/publicacoes/cartilha-lavagem-de-dinheiro-um-problema-mundial/, acessado em 20/08/2012, às 22:00:00.

COELHO, Ricardo Corrêa. Estado, governo e mercado, Florianópolis: UFSC, Brasília: CAPES, 2009.

CRUVELLIER, Thierrry. Court of remorse: inside the International Criminal Court for Rwanda, trd. Chari Voss, Madison: University of Wisconsin Press, 2006.

DOTTI, René Ariel. Curso de direito penal: parte geral, Rio de Janeiro: Forense, 2004.

EL PAÍS. El cartel de la droga más sanguinario se adueña del norte de Guatemala. Disponível em http://elpais.com/diario/2011/05/19/internacional/1305756002_850215.html, acessado em 19/05/2011, às 19:30:00.

FERRAJOLI, Luigi. Direito e razão: teoria do garantismo penal, 2 ed., trd. Juarez Tavares et al, São Paulo: RT, 2006, pp. 38-39.

GUGGENHEIM, Paul. Contribution a l'historie des sources du Droit des Gens, RCADI, vol. 94, 1958.

HÄBERLE, Peter. El estado constitucional, trad. Héctor Fix-Fierro, Cuidad de Mexico: UNAM, 2003.

HÄBERLE, Peter; KOTZER, Markus. De la soberanía al derecho constitucional común: palabras clave para un diálogo europeu-latinoamericano, trad. Héctor Fix-Fierro, Cuidad de Mexico: UNAM, 2003.

2007.

O estado constitucional cooperativo, trad. Marcos A. Maliska e Elisete Antoniuk, Rio de Janeiro: Renovar,

HAGAN, John. Justice in the Balcans: prosecuting war crimes in the Hague Tribunal, Chicago: Chicago University Press, 2003. 
JANKOV, Fernanda F. F. Direito internacional penal: mecanismo de implementação do Tribunal Penal Internacional, São Paulo: Saraiva, 2009.

JAPIASSÚ, C. E. Adriano. O Tribunal Penal Internacional: a internacionalização do direito penal, Rio de Janeiro: Lumen Juris, 2004.

JESCHECK, Hans-Heinrich. O objeto do Direito Penal Internacional e sua mais recente evolução, trad. Nilo Batista, in Revista de Penal n. 6, Rio de Janeiro: Borsoi, abril/junho de 1972, pp. 7-20.

KELSEN, Hans. Will the Judgment in the Nuremberg Trial Constitute a Precedent in International Law?, International Law Quaterly, v. 1, n. 2, summer 1947, pp. 15-171.

KOTZUR, Markus. A Soberania Hoje. Palavras-Chave para um Diálogo Europeu Latino-Americano Sobre um Atributo do Estado Constitucional Moderno, trd. Marcus V. X. de Oliveira e Gabriel G. de Godói, Revista Quaestio Iuris, Rio de Janeiro, 2012, pp. 1-19.

LAFER, Celso. Prefácio, in PERRONE-MOISÉS, Cláudia. Direito penal internacional: imunidades e anistias, São Paulo: Manole, 2012.

MAIA, Carlos Rodolfo Tigre. Lavagem de dinheiro, 2 ed., São Paulo: Malheiros, 2007.

MELLO, Celso D. de Albuquerque. Curso de direito internacional público, vol. 2, 11 ed., Rio de Janeiro: Renovar, 2002.

MORAES, Deomar de. Paraísos fiscais, centros offshore e lavagem de dinheiro, in Anais do Seminário internacional sobre lavagem de dinheiro, Cadernos do CJF n. 17. Disponível em http://www.cjf.jus.br/revista/seriecadernos/vol17.htm\#PARAÍSOS FISCAIS, CENTROS, acessado em 20/11/2011, às 16:32:00.

NINO, Carlos Santiano. Ética e direitos humanos, trad. Nélio Schneider, São Leopoldo: Editora Unisinos, 2011.

ORGANIZAÇÃO DAS NAÇÕES UNIDAS. "Principles of International Law Recognized in the Charter of the Nürnberg Tribunal and in the Judgement of the Tribunal", Yearbook of the International Law Comission, 1950, vol. II.

ESCRITÓRIO DAS NAÇÕES UNIDAS SOBRE DROGAS E CRIMES. Guia de estudos: Convenção Internacional para a Eliminação do Financiamento do Terrorismo e Lavagem de Dinheiro. Disponível em http://www.ri.pucminas.br/minionu/Guia-UNODC.pdf, acessado em 20/07/2012, às 17:22:00.

The globalization of crime: a transnational organized crime threat assessment, UNODC: Viena, 2010, pp. 16-17. Disponível em http://www.unodc.org/documents/data-and analysis/tocta/TOCTA_Report_2010_low_res.pdf, acessado em 15/02/2011, às 14:00:00.

PALAZZO, Francesco C. Valores constitucionais e direito penal, trad. Gérson Pereira dos Santos, Porto Alegre: SAFE, 1989.

PERRONE-MOISÉS, Cláudia. Direito penal internacional: imunidades e anistias, São Paulo: Manole, 2012.

SILVA SÁNCHEZ, Jesús-María. A expansão do direito penal. Aspectos da política criminal nas sociedades pósindustriais, $2^{a}$ ed., São Paulo: Editora Revista dos Tribunais. 
SCHABAS, William A. An introduction to the International Criminal Court, 4 ed., Cambridge: Cambridge University Press, 2011.

SOUZA, Artur de Brito Gueiros, JAPIASSÚ, Carlos Eduardo Adriano. Curso de direito penal: parte geral, Elsevier: Rio de Janeiro, 2012.

Trabalho enviado em 27 de outubro de 2017.

Aceito em 16 de abril de 2017. 